\title{
REDUCING EMISSION OF HARMFUL TOXIC SUBSTANCES BY TRUCKS IN THE ASPECT OF ANALYSIS OF SELECTED VEHICLE OPERATING PARAMETERS AND HUMAN FACTOR
}

\author{
Agnieszka Aleksandra Szokało \\ Lublin University of Technology, Mechanical Engineering Faculty \\ Institute of Transport, Combustion Engines and Ecology \\ Nadbystrzycka Street 36, 20-618 Lublin, Poland \\ e-mail:aszokalo@interia.pl
}

Marcin Rychter

State Higher Vocational School in Ciechanów, Faculty of Engineering and Economics

Department of Mechanics and Machine Building

Narutowicza Street 9, 06-400 Ciechanów, Poland

e-mail:rychter@poczta.fm

\begin{abstract}
Digital tachographs as devices recording the work of a lorry and driver's work are a constant factor in the work of a professional driver. It is therefore important to preserve the security of recording and storing electronic information. In this matter, cryptography also becomes an inseparable field of science. The control services set up to conduct roadside inspections do not detect all violations in the recording devices by encrypting information in information systems. One of the frequent vehicle operating parameters that can be falsified are the speed of the vehicle and its rotational speed, as well as the time and efficiency of the driver's work. These parameters affect the amount of fuel consumption. The reduction of fuel consumption translates directly to the reduction of harmful substances emitted by the car to the environment. Variable compression engines are becoming the future of motoring in the case of internal combustion engines. It is noticeable that there are more frequent deliberate of regulations; and more violations rules concerning the proper functioning of recording devices by recording driver activity. Current methods of preventing violations are insufficient. The article points out the violations related to the actual rotational speed of the crankshaft of the internal combustion engine in relation to the vehicle speed profile, which is directly related to the fuel consumption and the emission of harmful substances. The article describes the ways to reduce fuel consumption, of which the correct driving technique is important in addition to the previously marked parameters. The factors that increase the awareness of professional drivers in the aspect of proper driving techniques are described.
\end{abstract}

Keywords: eco-driving training, rotation speed, digital tachograph system, recording equipment, road transport

\section{Introduction}

The job of a professional driver differs from that of an ordinary passenger car driver. The truck driver must obey the traffic regulations as well as the regulations governing the driver's working time. The current regulations clearly specify how much time a driver can drive a vehicle during each day and in weekly and bi-weekly billing periods.

However, in order to properly read the periods regulating the activity of the driver, it is necessary to know the provisions of Polish and inter-national law. The problem, however, is the turmoil associated with the understanding and interpretation of the drivers' working hours. Many drivers are often unaware of inaccuracies. The problem becomes when the driver exceeds the time of work activity in an intentional and purposeful manner. The devices used in digital tachograph systems are becoming easier to break. Ways of deceiving the work of digital tachographs are becoming more and more, which will be discussed below. 
Drivers as the most common reasons for interfering with the work of the tachograph say that in this way they want to make up for the time spent in traffic jams, as a result of road accidents and bad weather. A frequent emerging factor is also pressure from the forwarder or dispatcher, the need to complete or complete the loading / unloading process on the notification.

The way by which we can accurately read the activity of the driver and the registered work of the digital tachograph are workshop cards. Among parameters read during calibration is operated by the parameter which is the constant of the $k$-size numerical determining the value of the input signal necessary to indicate and register the distance of one kilometre. This constant is expressed in impulses per kilometre $(k=\ldots$ imp / $\mathrm{km})$ [7].

\section{Parameters that affect engine performance}

Parameters that are recorded using digital recording equipment include on crankshaft rotational speed and engine power. Among other things, these parameters can be updated or confirmed using workshop card.

The rotational speed is called the crankshaft rotation frequency, in other words the amount of crankshaft rotation in a unit of time - seconds or minutes (rps or rpm). As the rotational speed increases, the time for subsequent transformations decreases, what results in a deterioration of the thermal energy conversion and increase in mechanical engine load due to the increase inertness power in crank and camshaft systems [10].

It can be stated that unit consumption is a measure of the overall efficiency of the engine. Fig. 1 shows the dependence of the change in unit fuel consumption. It is versus the change in the compression ratio in a spark-ignition engine. Reducing fuel consumption translates directly into the reduction of carbon dioxide emissions into the environment. In conclusion, the increase in the compression ratio affects both the reduction of fuel consumption, the reduction of emissions to the environment and the increase of the overall efficiency of the engine.

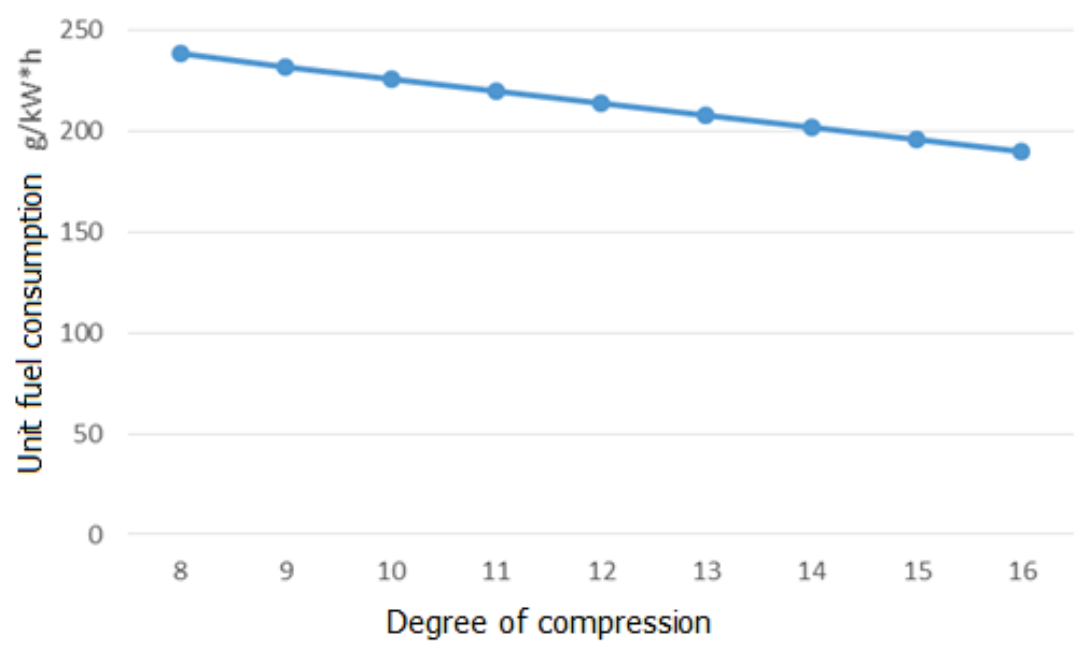

Fig. 1. Function of changing fuel consumption from change of compression ratio [2]

As a power engine, we understand the engine's ability to perform work. The engine of $1 \mathrm{~kW}$ is capable of raising the weight of about $102 \mathrm{kG}$ at the height of 1 meter in 1 second [6].

The amount of fuel consumed by the engine within a unit of time defines the concept of hourly fuel consumption. However, this unit consumption determines the amount of fuel consumed by the fuel engine during unit of time per unit of power [10]. That is why it is so important that the above-described parameters were measured and recorded correctly. Any interference in vehicle's speed record or the crankshaft rotation speed will not only affect the incorrect conduction of controls by authorized bodies, but also the falsification of actual vehicle's fuel consumption. 
The following figures show an example of vehicle speed profile report and a sample of speed profile report (Fig. 2). They are divided into 16 compartments and each individual compartment can be set individually during the installation of the digital recording equipment [8].
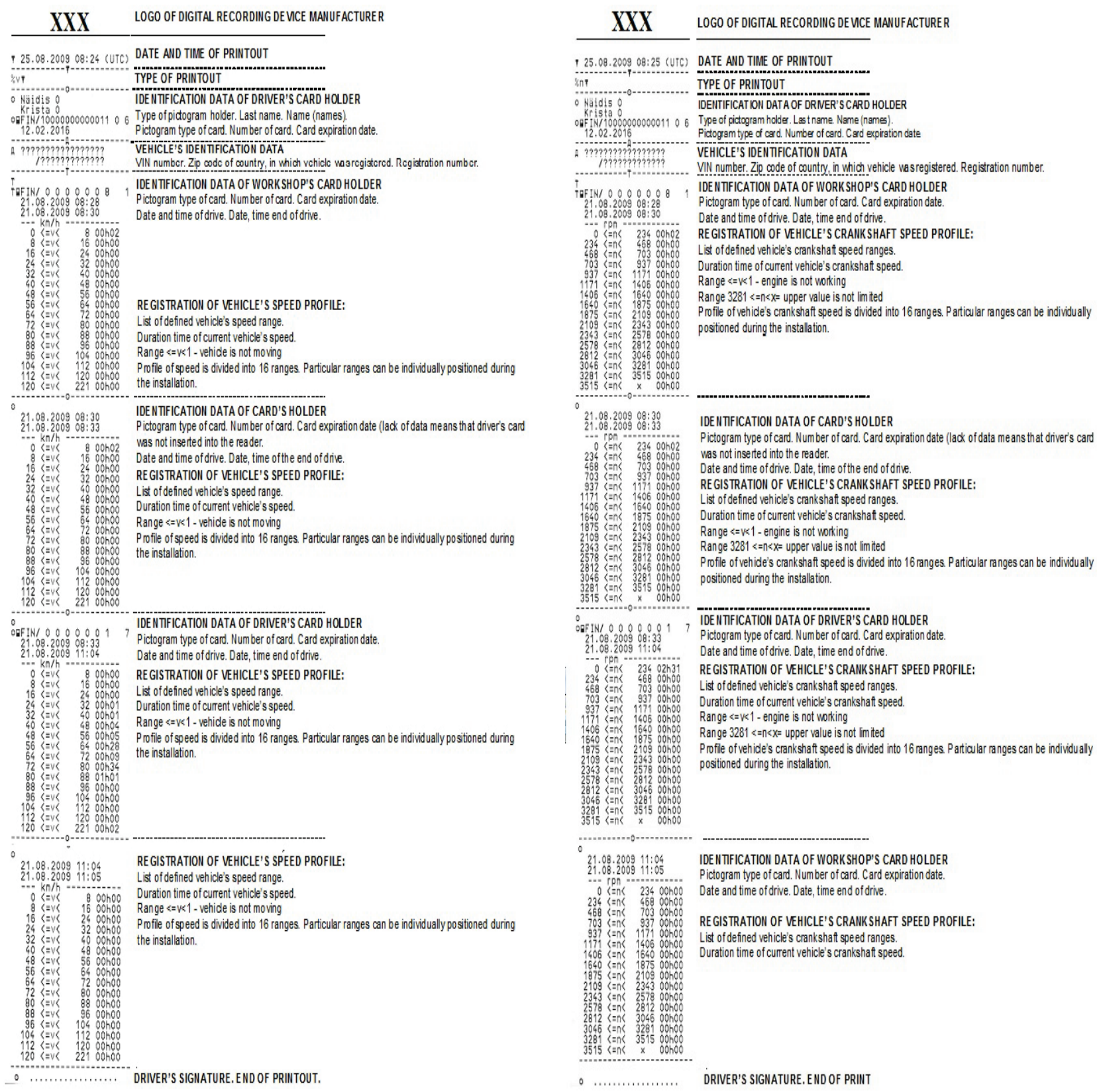

Fig. 2. Example of vehicle speed profile report [8]

The drivers' driving style and skills that directly affect fuel consumption can be read from the sample printouts of digital recording equipment. Of course, it cannot be assumed that only the driving style of the driver is responsible for the high fuel consumption of the vehicle. Largely the amount of consumed fuel also depends on the technical condition of the vehicle, the course of the route, weather conditions or traffic volume.

\section{Violations of STC work}

Every year, a significant number of cases are noticeable in which road traffic control authorities reveal the number of violations of tachograph work (see Fig. 3 and 4). It can be told 
that this number is slightly decreasing, which may affect greater number of vehicles on the roads that have digital recording devices installed (digital tachographs). However, the number of violations, in which the recording equipment did not register all the required elements, is increasing. This may indicate that those who indulge such practice are better trained also in the life cycle of the recording equipment.

\section{Amount of violations related to manipulation}
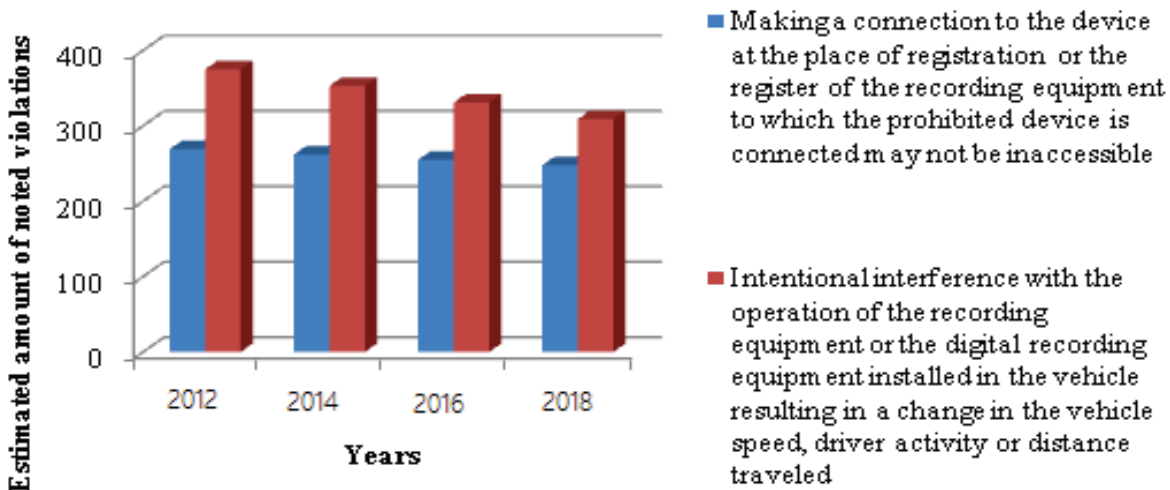

Fig. 3. Violation statistics for detected manipulations in vehicles equipped in recording devices or digital recording equipment [1]

Violation of regulations connected to using recording devices and digital recording devices

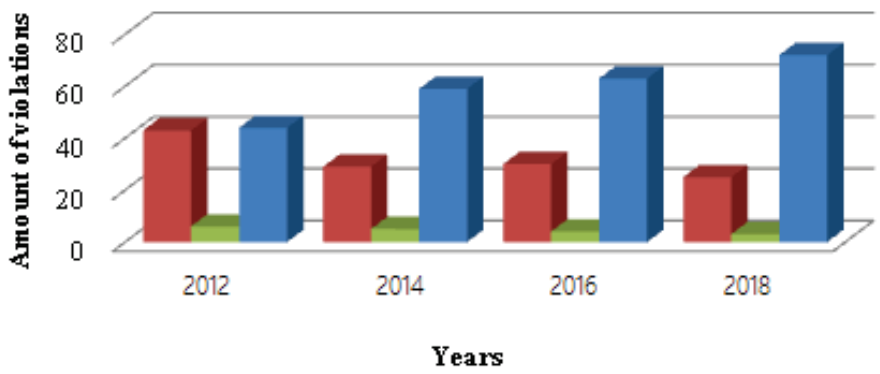

\footnotetext{
- Carrying by road driver with inoperative or incorrectly functioning recording equipm ent or digital recording device after expiry of the permitted driving period

nC arrying a road vehicle with a vehicle fitted with recording equipm ent or digital recording equipm ent that has been disconnected

nCarrying a road vehicle with a vehicle fitted with recording equipm ent or digital recording equipm ent that does not record all the required com ponents
}

Fig. 4. Violations of selected regulations on the use of recording equipment or digital recording equipment [1]

Because of the effects, two types of interference can be identified in the digital recording equipment. Incorrect records may result from [8]:

- inadequate programming of the on-board unit in terms of transmitting vehicle's speed information into recording device,

- the incorrect use of the executed activity switches,

- clock tuning or stopping,

- invalid manual entries,

- manner of writing changes. 
On the other hand, incomplete records or their absence may result from [8]:

- no working equipment,

- lack of vehicle's speed signal,

- lack of registers,

- not using the driver card,

- not doing manual entries.

It is noticeable, that the growing number of violations related to the incomplete recording of all required elements may directly come from the use of various types of means to interfere with the operation of the digital tachograph, e.g. the use of very strong magnets (Fig. 5).

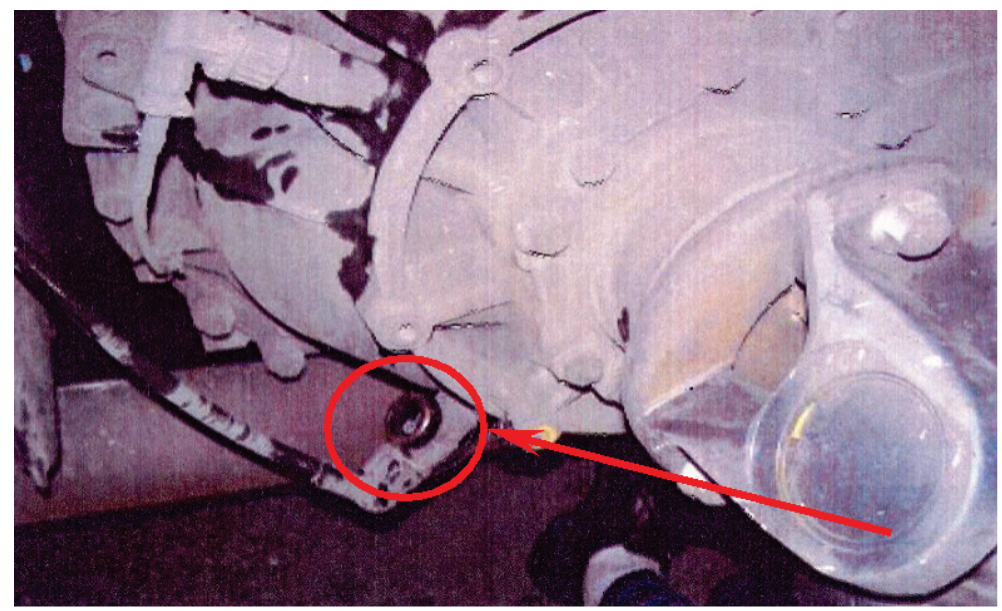

Fig. 5. Magnet on a motion sensor placed to manipulate the records of digital recording equipment [9]

Today, many vehicle functions use a speed signal directly from the tachograph. Disturbance of this signal or its deactivation causes many errors in the vehicle control unit. In some vehicles, the speed signal may also cause damage to the gearbox. Manufacturers began to protect themselves from these types of situations and introduced additional information in the vehicle's computer memory, which spoke of the user's distortion of the speed signal. The Dutch, French, and Polish inspection services often use diagnostic equipment to read errors from the vehicle's computer. By connecting to the OBD "On-Board Diagnostics" service connector; they are able to read faults of speed decay with accuracy of day and time.

All manipulations connected to changes in recordings on the driver card are very difficult to hide because each unauthorized change is recorded by the on-board unit.

Since the introduction of a digital tachograph whose construction is inseparable without permanent damage, the manipulation in the tachograph system was focused on the motion sensor mounted on the gearbox. The problem with the dishonest driver who made such manipulation was the correct power selection of the magnet, which was to deprive the sensor of the ability to send a speed and speed impulse. Often too strong magnet used, which on the sensor damage directly affected.

Locations describing the beginning and the end of the working day in combination with the recorded speed of the vehicle are used by persons authorized to conduct inspections to confirm the correctness of the recorded data on the driver's card. An example may be a change in the vehicle's speed signal, which often causes the recorded distance between two points to be shorter than the actual distance between those points [8].

Amounts of penalties for road carriage in order to violation of selected regulations on the use of automatic speed recorders, driving and stopping time [1]:

- performing road carriage with vehicle equipped in recording equipment or digital recording equipment to which an unauthorized device has been connected, affecting functioning of the recording equipment 2.000, 
- non-registration with recording device or digital recording device on a chart or driver's card indicating the device in terms of vehicle speed, driver's activity and distance traveled 2.000,

- performing road carriage with non-functional or inoperative recording equipment or digital recording device after expiration of the permitted driving period 1.000 ,

- road carriage of vehicle equipped in recording equipment or digital recording equipment which has been disconnected 2.000,

- intentionally interfering in operation of the recording equipment or the digital recording equipment installed in the vehicle, resulting in a change in the vehicle's speed, driver's activity or distance travelled 2.000 .

Selected penalties for violations of regulations on the use of recording equipment or digital devices automatically recording speed, driving and stopping time [1]:

- performing road carriage by the vehicle which is not equipped in recording equipment or digital recording equipment 3.000 ,

- performing road carriage by the vehicles equipped in recording equipment or digital recording equipment that does not record all required components 2.000 .

Any attempt to manipulate recorded data on a digital recorder is a significant danger in the carrier market, where fake driving conditions for wheeled vehicles may be a reason for existing unfair competition.

\section{Eco-driving}

The concept that in recent years is increasingly used is eco-driving. Reflecting on what ecodriving, the easiest to say is that it is an ability to drive economically. Not only economical driving, but also ecological one is important. There are number of factors that affect fuel consumption, which can easily reduce and thereby help to rebuild the transport fleet budget.

An important element is the aerodynamics of the vehicle. The more shape of the car will be streamlined, the smaller air resistance will be.

Another factor affecting the economical driving is the correct tire pressure in the vehicle. It should not be less than 0.5 bar from the pressure recommended by the manufacturer.

The load, that is the use of the load area in the largest possible way and most compliant to the traffic regulations, should be carried out with equal distribution of cargo and its protection.

Exterior conditions, and therefore atmospheric conditions, also have an impact on fuel consumption when snowing, raining, or snowstorm. It results in increasing vehicle resistance.

Traffic, speed, road are the factors that affect the combustion. Trainers suggest that in order to keeping a smoother ride without operating the gas pedal and the brake every now and then. It is important that the distance between the cars in the traffic should be adjusted to body's ability to react.

In order to reduce fuel consumption and prolonging the usage of the braking system, it is recommended for truck drivers to use retarders or engine brakes using a compulsory engine brake. In situations when it is safe, and we are longer time in one place, e.g. during the traffic, it is good to turn off the engine. The newest cars are equipped in the Start and go system, which saves the fuel.

The crucial subject matter in eco-driving is trainings. Nowadays, companies are eager to send their drivers on such trainings, as not only will it increase safety (by improving driving techniques), but it also reduces fuel consumption by $15 \%$ on average. Leading truck manufacturers in their portfolio have trainings for drivers.

Trainings take place not only in real road conditions but also on specially programmed driving simulators. These simulators use the EETS system, which automatically registers data and processes it by presenting a clear analysis of the driving style.

Exemplary training program offered by the Eco Driving Academy includes [3]:

- theoretical classes - to familiarize participants with Eco - driving premises - a reminder of economic driving, 
- practical classes - the first transit monitored by the EETS system - assessment of the student's ability and potential,

- Instructor's transit - demonstration of proper behaviour while driving,

- practical classes - second transit monitored by EETS system - implementation of Eco Driving principles,

- theoretical classes - discussion about all Eco Driving principles and discussion about the second transit and showing the differences between two transits based on the EETS report,

- end of training - summary.

The higher is the engine revs, the higher combustion will be. This does not mean, however, that you should ride between 1000-1500 rpm. Engine revs must be adjusted to the road situation. When we want to accelerate quickly, the engine should operate at higher speeds than when, for example, we drive down from a hill. Many drivers make the mistake of acceleration from very low revs - this is not an economical driving. The engine-controlling computer will open the valves as much as possible to speed up the car [5].

Simulator's characteristic [4]:

- the simulator is mounted in a specially built road trailer, which is a 14 meter long mobile training centre equipped in air-conditioned rooms,

- The realism of driving in the simulator has been polished to perfection: the driver's cab is no different from the standard one, and steering devices put natural resistance,

- all well-known equipment and systems such as ABS, EBS Full (including ESP option, overturn protection system), cruise control and much more are available for the driver,

- newest and best audio-visual systems, including surround sound and top-quality onscreen technology - directly on car's windowpane,

- 6 degrees of simulator freedom, the device moves vertically, horizontally and transversely,

- different variants of routes,

- changing atmospheric conditions,

- possibility to choose a vehicle from a very wide range, simulator allows to train on very different types of vehicles (truck, solo tractor, semitrailer, tanker, tipper, bus, special purpose vehicle),

- the vehicle is driven under different load conditions (full load, different load distribution, etc.). Advantages of trainings on the simulator [4]:

- multiple repeating the same situation,

- possibility of seeing the recording from the training,

- shaping the driving techniques based on eco-driving principles,

- possibility of any modification of the route,

- many vehicles with different loads,

- surprising situations on the road,

- the most difficult possible weather and road conditions,

- simulating driving after using drugs and alcohol,

- no fuel costs,

- no risk of vehicle's damage,

- safety of participants.

\section{Summary}

According to the data recorded by the authorities empowered to carry out checks traffic becomes more frequent dealings, are deliberately violated the principles of sound recording equipment functions the driver's employment. Persons committing this crime are most likely to use the connection of an unauthorized auxiliary device affecting the improper functioning of the recording equipment. Observation of driver's working time is more noticeable in recent years. The increase in violations is noticeable in the interruption of the registration of selected data. Among them is the speed by which we measure the speed of the vehicle. With these two parameters, we 
are able to give an indicative fuel consumption of the vehicle. Today, companies eager to benefit from training for drivers, who practice improve driving techniques. Training is intended to reduce the fuel consumed by a truck, by using the principles of eco-driving.

\section{References}

[1] Dane Głównego Inspektoratu Transportu Samochodowego 2013-2016, http://www.bialystok. witd.gov.pl/ images/pdf/taryfikator.pdf.

[2] Drabik, D., Analiza możliwości obniżenia zużycia paliwa w samochodach osobowych, Autobusy - Technika. Eksploatacja. Systemy Transportowe, Nr 6, pp. 613, 2017.

[3] http://ecodrivingacademy.com/categories/.

[4] http://www.cargo.edu.pl/mobilny-symulator-jazdy.

[5] http://www.technikjazdy.info/techniczne/eco-driving/.

[6] Karczewski, M., Szczuka, L., Tracinski, G., Silniki pojazdów samochodowych, WSiP, pp. 28, Warszawa 2013.

[7] Rozporządzenie Komisji (WE) nr 1360/2002, z dnia 13 czerwca 2002 r., dostosowujące po raz siódmy do postępu technicznego Rozporządzenie Rady (EWG) nr 3821/85 w sprawie urządzeń rejestrujących stosowanych w transporcie drogowym, pp. 287-288, 483-485, 492, 494.

[8] Rychter, M., Budowa $i$ zastosowanie system tachografii cyfrowej, Wydawnictwo Instytutu Transportu Samochodowego, pp. 21, 175-177, 197, 247-249, Warszawa 2011.

[9] Rychter, M., Forming recommendations of digital recording devices, Journal of Polish CIMAC, Vol. 7, No. 2, Diagnosis, reliability and safety, p. 187, 2012.

[10] Wajand, J. A., Wajand, J. T., Tłokowe silniki spalinowe średnio- $i$ szybkoobrotowe, WNT, pp. 129, 137, Warszawa 2005.

Manuscript received 17 June 2019; approved for printing 19 September 2019 